\title{
Inter-Facility Transfer vs. Direct Admission of Patients With ST-Segment Elevation Acute Myocardial Infarction Undergoing Primary Percutaneous Coronary Intervention
}

\author{
Kenji Nakatsuma, MD; Hiroki Shiomi, MD; Takeshi Morimoto, MD; Yutaka Furukawa, MD; \\ Yoshihisa Nakagawa, MD; Kenji Ando, MD; Kazushige Kadota, MD; Takashi Yamamoto, MD; \\ Satoru Suwa, MD; Minoru Horie, MD; Takeshi Kimura, MD \\ on behalf of the CREDO-Kyoto AMI investigators
}

\begin{abstract}
Background: Inter-facility transfer for primary percutaneous coronary intervention (PCI) from referring facilities to $\mathrm{PCl}$ centers causes a significant delay in treatment of ST-segment elevation acute myocardial infarction (STEMI) patients undergoing primary PCI. However, little is known about the clinical outcomes of STEMI patients undergoing inter-facility transfer in Japan.
\end{abstract}

\begin{abstract}
Methods and Results: In the CREDO-Kyoto acute myocardial infarction (AMI) registry that enrolled 5,429 consecutive AMI patients in 26 centers in Japan, the current study population consisted of 3,820 STEMI patients who underwent primary $\mathrm{PCl}$ within $24 \mathrm{~h}$ of symptom onset. We compared long-term clinical outcomes between interfacility transfer patients and those directly admitted to $\mathrm{PCl}$ centers. The primary outcome measure was a composite of all-cause death or heart failure (HF) hospitalization. There were 1,725 (45.2\%) inter-facility transfer patients, and 2,095 patients $(54.8 \%)$ with direct admission to $\mathrm{PCl}$ centers. The cumulative 5 -year incidence of death/HF hospitalization was significantly higher in the inter-facility transfer patients than in those with direct admission $(26.9 \%$ vs. $22.2 \%$; log-rank $\mathrm{P}<0.001$ ). After adjusting for potential confounders, the risk for death/HF hospitalization was significantly higher (adjusted hazard ratio: 1.22, 95\% confidence interval: $1.07-1.40, \mathrm{P}<0.001$ ) in the inter-facility transfer patients than in those directly admitted.
\end{abstract}

Conclusions: Inter-facility transfer was associated with significantly worse long-term clinical outcomes for patients with STEMI undergoing primary PCI. (Circ J 2016; 80: 1764-1772)

Key Words: Angioplasty; Myocardial infarction; Reperfusion

$\mathbf{P}$ rimary percutaneous coronary intervention (PCI) has replaced fibrinolysis as the preferred reperfusion strategy in ST-segment elevation acute myocardial infarction (STEMI) patients if it is performed in a timely fashion., ${ }^{1,2}$ The efforts to minimize door-to-balloon (DTB) time achieved a temporal decrease in DTB time in the USA, but an expected mortality reduction has so far not been observed. ${ }^{3,4}$ The focus of minimizing ischemic time in STEMI has, therefore, moved from only hospital delay in the DTB time to total ischemic time including prehospital delay. ${ }^{5-9}$ Inter-facility transfer for primary PCI from referring facilities to PCI-capable facilities may cause a significant treatment delay for STEMI patients undergoing primary PCI. The American College of Cardiology Foundation/American Heart Association (ACC/AHA) guidelines for STEMI recommend transport directly to a PCIcapable facility for primary PCI as Class 1 (level of evidence

Received February 29, 2016; revised manuscript received May 5, 2016; accepted May 24, 2016; released online June 28, 2016 Time for primary review: 24 days

Department of Cardiovascular Medicine, Graduate School of Medicine, Kyoto University, Kyoto (K.N., H.S., T.K.); Department of Clinical Epidemiology, Hyogo College of Medicine, Nishinomiya (T.M.); Division of Cardiology, Kobe City Medical Center General Hospital, Kobe (Y.F.); Division of Cardiology, Tenri Hospital, Tenri (Y.N.); Division of Cardiology, Kokura Memorial Hospital, Kitakyushu (K.A.); Division of Cardiology, Kurashiki Central Hospital, Kurashiki (K.K.); Department of Cardiovascular and Respiratory Medicine, Shiga University of Medical Science, Otsu (T.Y., M.H.); and Division of Cardiology, Juntendo University Shizuoka Hospital, Izunokuni (S.S), Japan

Mailing address: Hiroki Shiomi, MD, PhD, Department of Cardiovascular Medicine, Kyoto University Graduate School of Medicine, 54 Kawahara-cho, Shogoin, Sakyo-ku, Kyoto 606-8507, Japan. E-mail: hishiomi@kuhp.kyoto-u.ac.jp

ISSN-1346-9843 doi:10.1253/circj.CJ-16-0204

All rights are reserved to the Japanese Circulation Society. For permissions, please e-mail: cj@j-circ.or.jp 


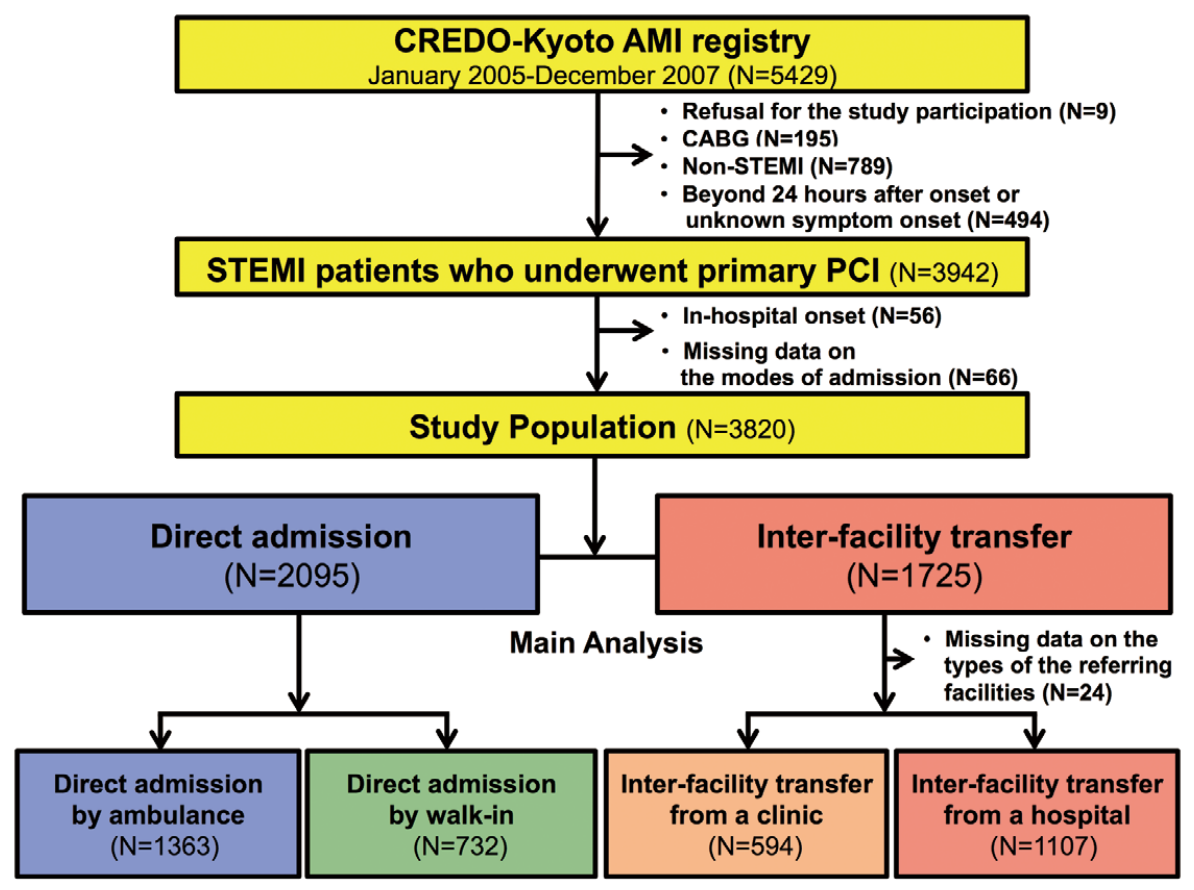

Figure 1. Flow chart for selection of the study population. AMI, acute myocardial infarction; CABG, coronary artery bypass grafting; $\mathrm{PCl}$, percutaneous coronary intervention; STEMI, ST-segment elevation acute myocardial infarction.

B). ${ }^{1}$ Approximately $20-45 \%$ of STEMI patients, however, were reported to having been initially admitted to a referring facility and subsequently transferred to PCI-capable facilities for primary PCI. ${ }^{10-20}$ Several previous studies have reported the outcomes of STEMI patients having inter-facility transfer as compared with those with direct admission, but the results are inconsistent because of the range of treatment delays caused by inter-facility transfer, the different risk profiles of the patients and the different sizes of the studies. ${ }^{10-20}$ The purpose of the present study, therefore, was to evaluate the influence of inter-facility transfer on long-term clinical outcomes of STEMI patients who underwent primary PCI, using a large observational database of patients with acute myocardial infarction (AMI) in Japan.

\section{Editorial $p 1700$}

\section{Methods}

The Coronary REvascularization Demonstrating Outcome Study in Kyoto (CREDO-Kyoto) AMI registry is a physicianinitiated non-company-sponsored multicenter registry that enrolled consecutive patients with AMI who underwent coronary revascularization within 7 days of the onset of symptoms between January 2005 and December 2007 at 26 hospitals in Japan (Appendix S1). The relevant review board or ethics committee at all 26 participating hospitals approved the study protocol. Obtaining written informed consent from the patients was waived because of the retrospective nature of the study; however, we excluded those patients who refused participation in the study when contacted at follow-up. This strategy is concordant with the guidelines of the Japanese Ministry of Health, Labor and Welfare. The details on the design and patient enrollment of this registry have been described previously. ${ }^{7}$ Among 5,429 patients enrolled in this registry, we excluded 9 patients who refused to participate in the study, 195 patients treated by coronary artery bypass grafting surgery, 789 patients with non-STEMI, 494 patients who underwent PCI beyond $24 \mathrm{~h}$ of symptom onset or whose symptom onset was unknown, 56 patients with in-hospital onset of STEMI, and 66 patients for whom the data on the mode of admission to the PCI center was not available (Figure 1). Therefore, the study population for the current analysis consisted of 3,820 STEMI patients who underwent primary PCI within $24 \mathrm{~h}$ of symptom onset. There were 1,725 inter-facility transfer patients (45.2\%), and 2,095 patients (54.8\%) directly admitted to PCI centers. Experienced clinical research coordinators from an independent clinical research organization (Research Institute for Production Development, Kyoto, Japan; Appendix S2) collected baseline data from the hospital charts or hospital databases according to prespecified definitions. Collection of follow-up information was mainly conducted through review of the inpatient and outpatient hospital charts by the clinical research coordinators, and additional follow-up information was collected through contact with patients, relatives and/or referring physicians by mail with questions regarding vital status, subsequent hospitalizations, and status of antiplatelet therapy. The transfer distance was calculated using the Advanced Core Technology Distance Calculation Worksheet for Excel $^{\circledR}$.

The inter-facility transfer group consisted of patients who were transferred for primary PCI from the referring facilities to a PCI center (participating centers), and the direct admission group consisted of those admitted directly to the PCI centers. The detailed definitions of baseline clinical characteristics are given in Supplementary Methods. 
The primary outcome measure for the current analysis was a composite of all-cause death and heart failure (HF) hospitalization, consistent with our previous report. ${ }^{7}$ The secondary outcome measures included all-cause death, cardiac death, and HF hospitalization. Death was regarded as cardiac in origin unless obvious non-cardiac causes could be identified. Any death during hospitalization for the index AMI was regarded as cardiac death. HF hospitalization was regarded as present when intravenous drug treatment was administered for worsening HF during hospitalization. Death, cardiac death, and HF hospitalization were adjudicated by the clinical event committee (Appendix S3).

\section{Statistical Analysis}

We present continuous variables as mean \pm standard deviation or median with interquartile range $[\mathrm{IQR}]$, and categorical variables as numbers and percentages. We compared continuous variables with Student's t-test or Wilcoxon rank-sum test on the basis of the distributions. We compared categorical variables with the $\chi^{2}$ test when appropriate; otherwise, we used Fisher's exact test. We used the Kaplan-Meier method to estimate cumulative incidences of clinical event rates and assessed differences with the log-rank test. The effects of inter-facility transfer relative to direct admission for individual endpoints were expressed as hazard ratios with $95 \%$ confidence intervals by multivariable Cox proportional hazard models adjusting for the 39 clinically relevant factors indicated in Table 1 . Consistent with our previous reports, continuous variables were dichotomized using clinically meaningful reference values or median values. To further investigate the effect of the mode of admission to the PCI centers on long-term clinical outcomes, we subdivided the patients into 4 groups: direct admission (by ambulance or walk-in) and inter-facility transfer (from a hospital or a clinic). The effects of walk-in, transfer from a hospital, and transfer from a clinic were evaluated using direct admission by ambulance as the reference in the same multivariable Cox proportional hazard models with dummy variables. Statistical analyses were conducted using JMP 10.0 (SAS Institute Inc, Cary, NC, USA). All the statistical analyses were 2-tailed. We regarded $\mathrm{P}<0.05$ as statistically significant.

\section{Results}

Among the 1,725 patients who were transferred from referring facilities to the PCI centers, the median inter-facility transfer distance was 8.5 (IQR: 3.7-20.5) km. The majority of interfacility transfer patients were transferred to relatively nearby PCI centers in the present study $(\leq 20 \mathrm{~km}$ in $74 \%$ of patients)

\begin{tabular}{|c|c|c|c|}
\hline & $\begin{array}{l}\text { Direct admission } \\
\quad(n=2,095)\end{array}$ & $\begin{array}{l}\text { Inter-facility transfer } \\
\qquad(n=1,725)\end{array}$ & $P$ value \\
\hline \multicolumn{4}{|l|}{ Baseline characteristics } \\
\hline Age (years) & $66.5 \pm 12.2$ & $68.6 \pm 12.3$ & $<0.001$ \\
\hline$\geq 75$ years $^{\star}$ & $577(28)$ & $599(35)$ & $<0.001$ \\
\hline Male sex ${ }^{\star}$ & $1,610(77)$ & $1,214(70)$ & $<0.001$ \\
\hline $\mathrm{BMI}<25.0\left(\mathrm{~kg} / \mathrm{m}^{2}\right)^{*}$ & $1,481(71)$ & $1,275(74)$ & 0.03 \\
\hline Hypertension* & $1,635(78)$ & $1,349(78)$ & 0.91 \\
\hline Diabetes mellitus & $647(31)$ & $561(33)$ & 0.74 \\
\hline Treated with insulin* & $86(4.1)$ & $74(4.3)$ & 0.78 \\
\hline Current smoker* & $875(42)$ & $681(39)$ & 0.15 \\
\hline $\mathrm{HF}^{\star}$ & $653(32)$ & $529(31)$ & 0.74 \\
\hline Mitral regurgitation grade $3 / 4^{*}$ & 67 (3.2) & $39(2.3)$ & 0.08 \\
\hline Ejection fraction $\leq 40 \%$ & $266(16)$ & $224(17)$ & 0.37 \\
\hline Previous $\mathrm{Ml}^{\star}$ & $235(11)$ & $102(5.9)$ & $<0.001$ \\
\hline Previous stroke (symptomatic) ${ }^{\star}$ & $175(8.4)$ & $154(8.9)$ & 0.53 \\
\hline Peripheral vascular disease ${ }^{\star}$ & $68(3.4)$ & $48(2.8)$ & 0.41 \\
\hline eGFR $\left(\mathrm{ml} / \mathrm{min} / 1.73 \mathrm{~m}^{2}\right)$ & $67.9 \pm 22.5$ & $71.1 \pm 29.2$ & $<0.001$ \\
\hline eGFR <30, without hemodialysis* & $72(3.4)$ & $84(4.9)$ & 0.03 \\
\hline Hemodialysis $^{\star}$ & $21(1.0)$ & $31(1.8)$ & 0.03 \\
\hline Atrial fibrillation* & $191(9.1)$ & $162(9.4)$ & 0.77 \\
\hline Anemia (hemoglobin $<11.0 \mathrm{~g} / \mathrm{dl}$ ) & $134(6.4)$ & $202(12)$ & $<0.001$ \\
\hline Thrombocytopenia (platelets $<100 \times 10^{9} / \mathrm{L}$ ) ${ }^{*}$ & $41(2.0)$ & $27(1.6)$ & 0.36 \\
\hline Chronic obstructive pulmonary disease * & $76(3.6)$ & $51(3.0)$ & 0.25 \\
\hline Liver cirrhosis* & $53(2.5)$ & $34(2.0)$ & 0.25 \\
\hline Malignancy* & $177(8.5)$ & $117(6.8)$ & 0.055 \\
\hline \multicolumn{4}{|l|}{ Presentation } \\
\hline \multicolumn{4}{|l|}{ Hemodynamics } \\
\hline Killip class 1 & $1,554(74)$ & $1,306(75)$ & \multirow{4}{*}{0.02} \\
\hline Killip class 2 & $159(7.6)$ & $155(9.0)$ & \\
\hline Killip class 3 & $49(2.3)$ & $46(2.7)$ & \\
\hline Killip class $4^{*}$ & $333(16)$ & $218(13)$ & \\
\hline Intra-aortic balloon pump use & $357(17)$ & $260(15)$ & 0.10 \\
\hline
\end{tabular}




\begin{tabular}{|c|c|c|c|}
\hline & $\begin{array}{l}\text { Direct admission } \\
\quad(n=2,095)\end{array}$ & $\begin{array}{l}\text { Inter-facility transfer } \\
(\mathrm{n}=1,725)\end{array}$ & $P$ value \\
\hline \multicolumn{4}{|l|}{ Angiographic characteristics } \\
\hline \multicolumn{4}{|l|}{ Infarct-related artery location } \\
\hline Left anterior descending artery & $944(45)$ & $818(47)$ & \\
\hline Left circumflex artery & $222(11)$ & $157(9.1)$ & \\
\hline Right coronary artery & $856(41)$ & $716(42)$ & 0.009 \\
\hline Left main coronary artery & $57(2.7)$ & $31(1.8)$ & \\
\hline Coronary artery bypass graft & $16(0.8)$ & $3(0.2)$ & \\
\hline Multivessel disease ${ }^{\star}$ & $1,133(54)$ & $892(52)$ & 0.14 \\
\hline No. of target lesions & $1.38 \pm 0.67$ & $1.42 \pm 0.74$ & 0.08 \\
\hline Target of proximal left anterior descending artery* & $1,114(53)$ & $969(56)$ & 0.06 \\
\hline Target of unprotected left main coronary artery ${ }^{\star}$ & $80(3.8)$ & $51(3.0)$ & 0.15 \\
\hline Target of chronic total occlusion* & $62(3.0)$ & $60(3.5)$ & 0.36 \\
\hline Target of bifurcation* & $520(25)$ & $476(28)$ & 0.052 \\
\hline Side-branch stenting ${ }^{*}$ & $55(2.6)$ & $61(3.5)$ & 0.10 \\
\hline Total stent length $>28 \mathrm{~mm}^{*}$ & $792(41)$ & $689(43)$ & 0.20 \\
\hline Minimum stent size $<3.0 \mathrm{~mm}^{*}$ & $554(29)$ & $545(34)$ & $<0.001$ \\
\hline Drug-eluting stent use (culprit or other lesion)* & $594(28)$ & $515(30)$ & 0.31 \\
\hline \multicolumn{4}{|l|}{ Drugs at discharge } \\
\hline \multicolumn{4}{|l|}{ Antiplatelet therapy } \\
\hline Thienopyridine & $1,984(95)$ & $1,662(96)$ & 0.02 \\
\hline Ticlopidine & $1,835(93)$ & $1,511(91)$ & 0.08 \\
\hline Clopidogrel & $148(7.5)$ & $151(9.1)$ & 0.08 \\
\hline Aspirin & $2,059(98)$ & $1,703(98.7)$ & 0.27 \\
\hline Cilostazol ${ }^{*}$ & 675 (32) & $688(40)$ & $<0.001$ \\
\hline \multicolumn{4}{|l|}{ Other medications } \\
\hline Statins* & $1,185(55)$ & $895(52)$ & 0.004 \\
\hline$\beta$-blockers* & $937(45)$ & $644(37)$ & $<0.001$ \\
\hline ACEI/ARB* & $1,542(74)$ & $1,236(72)$ & 0.18 \\
\hline Nitrates* & $552(26)$ & $563(33)$ & $<0.001$ \\
\hline Calcium-channel blockers ${ }^{*}$ & $434(21)$ & $325(19)$ & 0.15 \\
\hline Nicorandil ${ }^{*}$ & $648(31)$ & $440(26)$ & $<0.001$ \\
\hline Warfarin* & $236(11)$ & $172(10)$ & 0.20 \\
\hline Proton pump inhibitors* & $705(34)$ & $590(34)$ & 0.72 \\
\hline $\mathrm{H}_{2}$-blockers* & $663(32)$ & $617(36)$ & 0.007 \\
\hline
\end{tabular}

${ }^{*}$ Potential independent variables selected for Cox proportional hazard models. Categorical variables are expressed as $\mathrm{n}(\%)$ unless otherwise indicated. Continuous variables are shown as mean \pm standard deviation or median (interquartile range). ACEI, angiotensin-converting enzyme inhibitors; ARB, angiotensin-receptor blockers; BMI, body mass index; eGFR, estimated glomerular filtration rate, calculated by the Modification of Diet in Renal Disease formula modified for Japanese patients; HF, heart failure; MI, myocardial infarction; PCl, percutaneous coronary intervention; STEMI, ST-segment elevation acute MI.

(Figure 2). Baseline clinical characteristics were different in several important aspects between the inter-facility transfer and direct admission groups. The inter-facility transfer group had a significantly higher prevalence of patients with advanced age and anemia, while the direct admission group had significantly more patients with prior MI, male sex, renal dysfunction, and malignancy. The prevalence of cardiogenic shock was significantly higher in the direct admission group than in the inter-facility transfer group (Table 1). Regarding medical treatment at discharge, $\beta$-blockers and nicorandil were more often prescribed in the direct admission group, whereas thienopirydine, nitrates, and $\mathrm{H}_{2}$-blokers were more often prescribed in the inter-facility transfer group (Table 1). Onset-to-presentation (to the PCI center) time was significantly longer in the inter-facility transfer group than in the direct admission group, while DTB time was significantly shorter in the inter-facility transfer group than in the direct admission group. Ultimately, onset-to-balloon (OTB) time was significantly longer in the inter-facility transfer group than in the direct admission group
(Figure 3).

Median follow-up duration for the surviving patients was 5.0 (IQR: 4.1-5.9) years (direct admission group: 5.0 (4.1-5.9) years; inter-facility transfer group: $4.9(1.0-5.9)$ years, $\mathrm{P}=0.003)$. Complete 1-, 3- and 5-year follow-up information was obtained in $98.3 \%, 96.1 \%$, and $70.2 \%$ of the patients, respectively. Compared with the direct admission group, the cumulative 5-year incidence of death/HF hospitalization was significantly higher in the inter-facility transfer patients than in those with direct admission (Figure 4). After adjusting for potential confounders, the excess risk of inter-facility transfer relative to direct admission for death/HF hospitalization was significant (Table 2). Inter-facility transfer as compared with direct admission was also associated with significantly higher risk of death and with a trend for higher risk of cardiac death (Table 2). The unadjusted and adjusted risks for HF hospitalization were not significantly different between the 2 groups (Table 2 ).

Among the 1,725 patients in the inter-facility transfer group, 1,107 were transferred from a hospital and 594 from a clinic. 


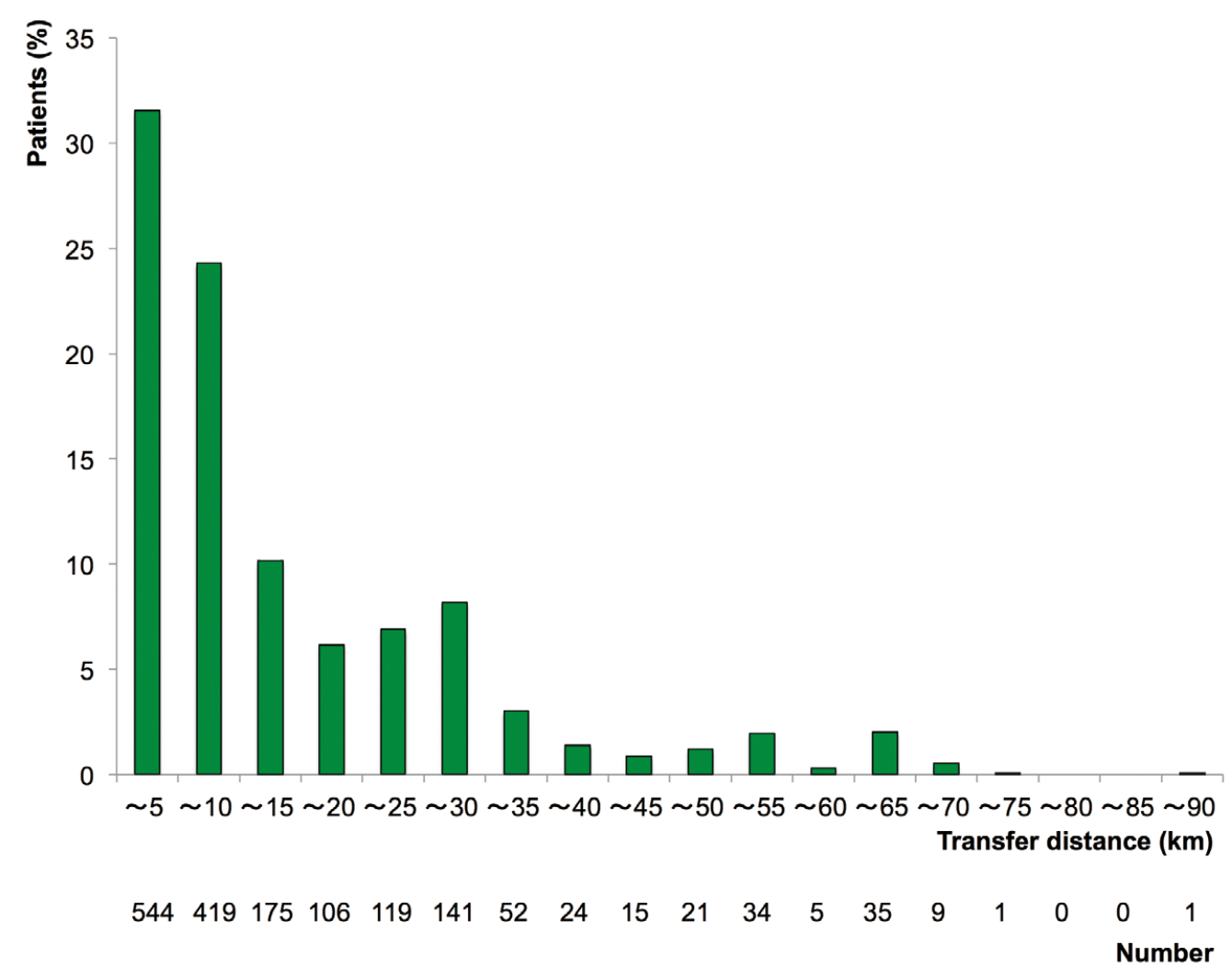

Figure 2. Distribution of inter-facility transfer distance.

(A) Onset to presentation time

(B) Door to balloon time

(C) Onset to balloon time
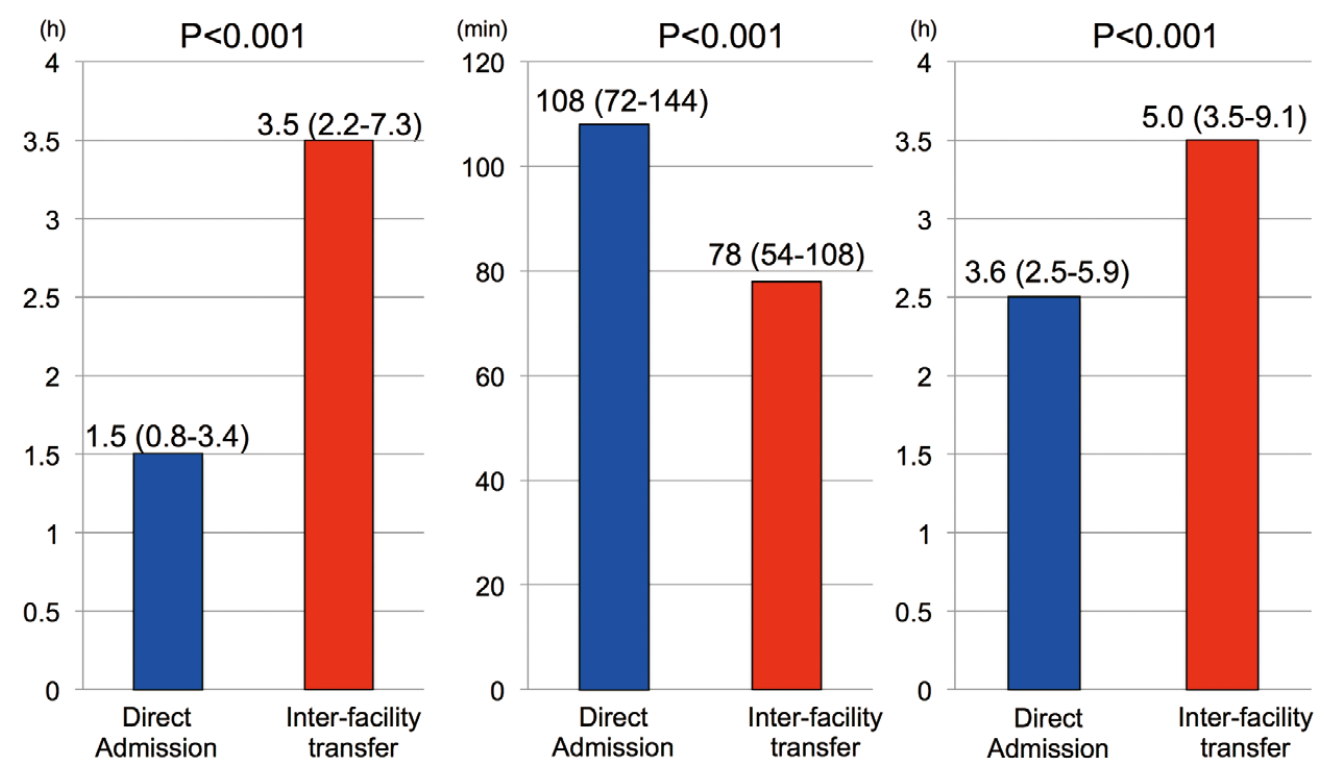

Figure 3. (A) Onset-to-presentation, (B) door-to-balloon and (C) onset-to-balloon time: direct admission vs. inter-facility transfer. 


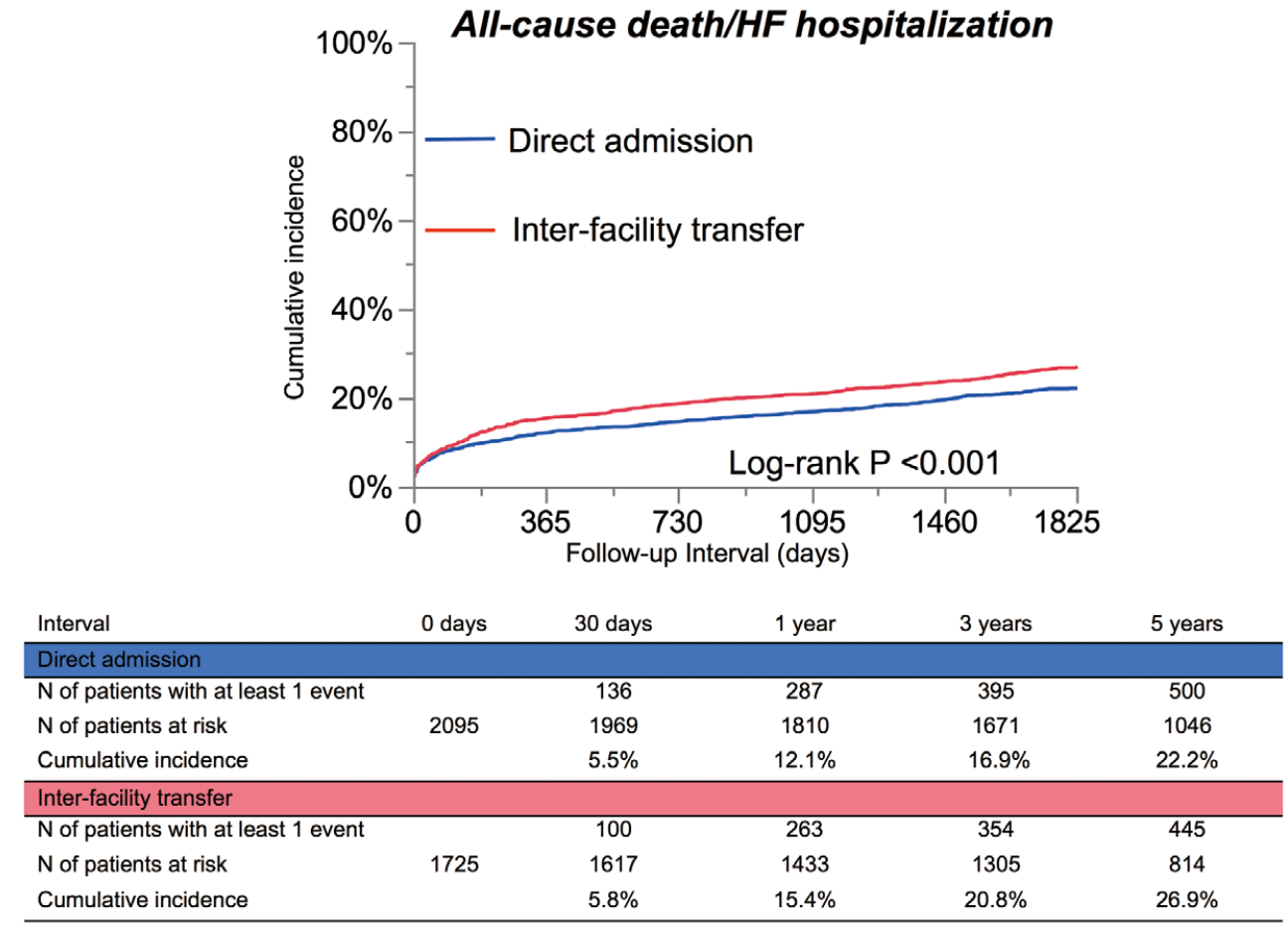

Figure 4. Cumulative 5-year incidence of the composite of death or heart failure (HF) hospitalization compared between direct admission and inter-facility transfer.

\begin{tabular}{|c|c|c|c|c|c|c|}
\hline & Direct admission & Inter-facility transfer & P value & & sted & P yalue \\
\hline & $(n=2,095)$ & $(n=1,725)$ & r value & HR & $95 \% \mathrm{Cl}$ & r value \\
\hline \multicolumn{7}{|l|}{ Peak cardiac enzymes } \\
\hline Peak CPK (IU/L) & $2,253(1,145-4,167)$ & $2,473(1,199-4,569)$ & 0.02 & - & - & - \\
\hline Peak CK-MB (IU/L) & $192(91-371)$ & $196(88-347)$ & 0.16 & - & - & - \\
\hline \multicolumn{7}{|l|}{ Clinical outcomes } \\
\hline $\begin{array}{l}\text { All-cause death/HF } \\
\text { hospitalization }\end{array}$ & $500(22.2 \%)^{*}$ & $445(26.9 \%)^{*}$ & $<0.001$ & 1.22 & $(1.07-1.40)$ & 0.003 \\
\hline All-cause death & $386(17.7 \%)^{*}$ & $400(22.2 \%)^{\star}$ & $<0.001$ & 1.23 & $(1.05-1.44)$ & 0.01 \\
\hline Cardiac death & $231(10.7 \%)^{*}$ & $228(12.9 \%)^{\star}$ & 0.03 & 1.20 & $(0.98-1.48)$ & 0.08 \\
\hline HF hospitalization & $163(8.4 \%)^{\star}$ & $134(8.6 \%)^{*}$ & 0.77 & 1.12 & $(0.86-1.44)$ & 0.40 \\
\hline
\end{tabular}

${ }^{*}$ Number of patients with event (cumulative 5-year incidence). $\mathrm{Cl}$, confidence interval; $\mathrm{CPK}$, creatine phosphokinase; HR, hazard ratio. Other abbreviations as in Table 1.

Among the 2,095 patients in the direct admission group, 1,363 and 732 patients, respectively, were admitted to the PCI centers by ambulance and by walk-in. The baseline clinical characteristics were mostly similar between the 2 inter-facility transfer groups (from a hospital or a clinic) and between the 2 direct admission groups (by ambulance or by walk-in) (Table S1). Regarding hemodynamics, however, the "direct admission by ambulance" group and the "inter-facility transfer from a hospital" group, respectively, included more patients with hemodynamic compromise such as cardiogenic shock and mechanical support use than the "direct admission by walk-in" group and the "inter-facility transfer from a clinic" group (Table S1). The onset-to-presentation (to the PCI centers) time in the "direct admission by ambulance" group was markedly shorter than in the other 3 groups (Figure S1). On the other hand, DTB time in the "direct admission by walk-in" group was much longer than in the other 3 groups (Figure S1). Finally, the total ischemic time as represented by OTB time was markedly shorter in the "direct admission by ambulance" group than in the other 3 groups (Figure S1).

Reflecting the low-risk profile of patients included, the cumulative 5-year incidences of death/HF hospitalization were low in the "direct admission by walk-in" and "inter-facility transfer from a clinic" groups (Figure 5). The cumulative 5-year incidence of death/HF hospitalization in the "inter-facility transfer from a hospital" group was much higher than that in 


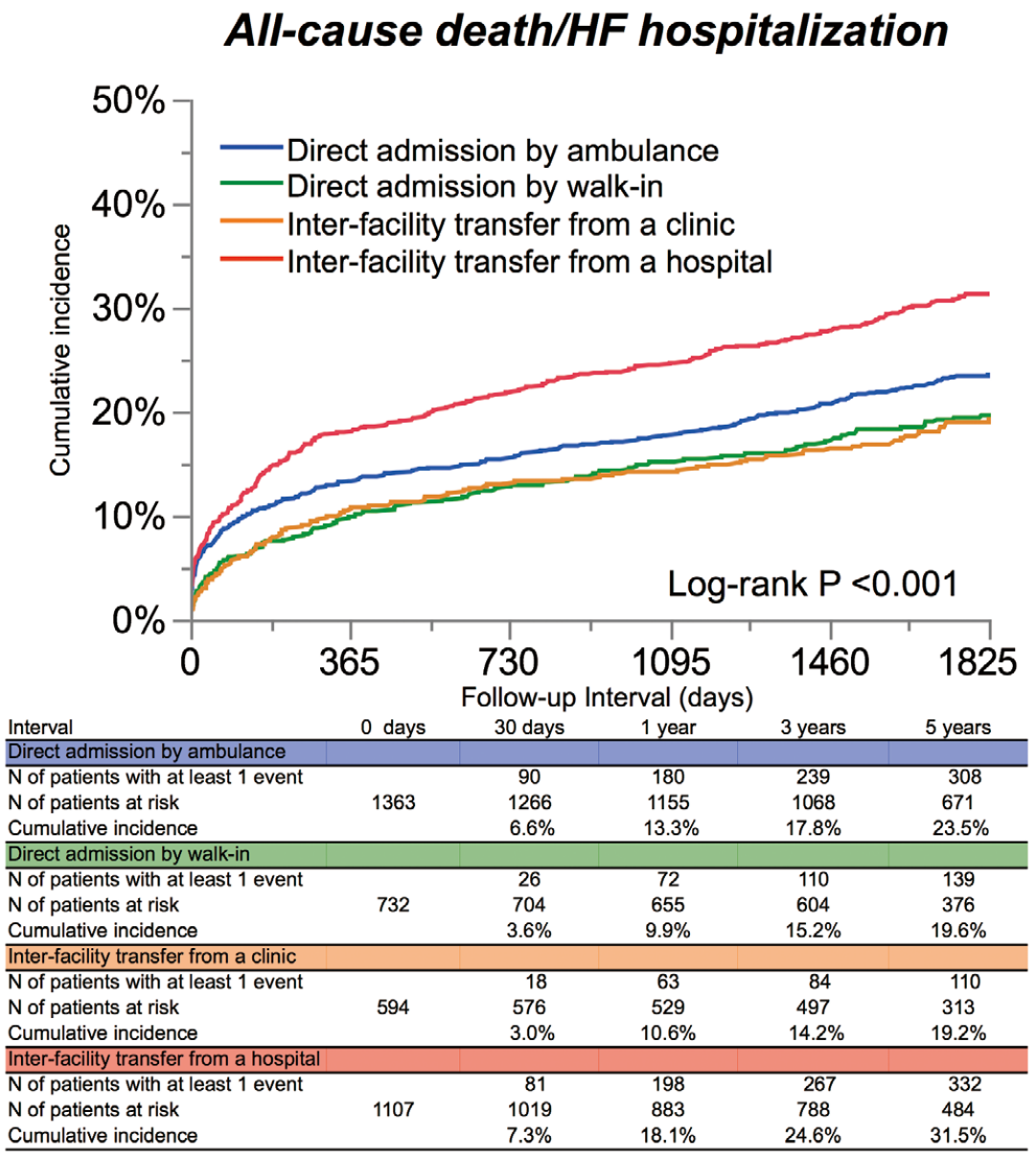

Figure 5. Cumulative 5-year incidence of the composite of death or heart failure (HF) hospitalization compared according to the mode of admission to the $\mathrm{PCl}$ center: direct admission by ambulance or by walk-in and inter-facility transfer from a clinic or a hospital. PCl, percutaneous coronary intervention.

the "direct admission by ambulance" group (Figure 5). The excess risk of the "inter-facility transfer from a hospital" group relative to the "direct admission by ambulance" group remained significant after adjusting for confounders (Tables 3,S2-S5).

\section{Discussion}

The main finding in the current study was that inter-facility transfer for primary PCI was associated with significantly longer total ischemic time and worse long-term clinical outcomes for STEMI patients.

Inter-facility transfer for primary PCI incurred a 84-min treatment delay as compared with direct admission to the PCI centers, resulting in significantly increased long-term risks of inter-facility transfer relative to direct admission for the composite of death/HF hospitalization and all-cause death in the current study. In the current study, $45.2 \%$ of STEMI patients were transferred from referring facilities for primary PCI in Japan where nearby PCI centers are available, particularly in urban areas. ${ }^{21}$ Several previous studies also reported that $20-45 \%$ of STEMI patients were initially admitted to a referring facility and then transferred to PCI-capable facilities for primary PCI. ${ }^{10-20}$ The clinical effect of inter-facility transfer relative to direct admission in those studies was inconsistent. Some research has found that STEMI patients with inter-facility transfer were at increased risk of death after STEMI, ${ }^{15-17,20}$ though others have not confirmed this finding. ${ }^{10-14,18,19}$ However, many previous studies evaluating the clinical effect of inter-facility transfer for primary PCI report a treatment delay of around $60 \mathrm{~min}$. In line with the current study, only $13 \%$ of inter-facility transfer patients were reported to be treated with PCI within $90 \mathrm{~min}$ of arrival at non-PCI centers. ${ }^{22}$ To avoid treatment delay caused by inter-facility transfer for primary PCI and to increase the rate of direct admission by ambulance therefore, prehospital diagnosis of STEMI and direct admission to a PCI center by ambulance should be pursued. Le May et al reported that inter-hospital transfer patients were associated with significantly increased mortality rates at 180 days as compared with those with direct admission by ambulance after a prehospital 12-channel ECG. ${ }^{16}$ Fosbøl et al also reported that using prehospital ECG and then bypassing geographically closer hospitals without primary PCI capabilities was associated with shorter total ischemic times and 3-fold greater likelihood of achieving the guideline target of $<90 \mathrm{~min}$ from first medical contact to PCI. ${ }^{18}$ This strategy has been implemented in several countries, ${ }^{5,14}$ and has been proposed as one of the 


\begin{tabular}{|c|c|c|c|c|c|}
\hline & \multirow{2}{*}{$\begin{array}{l}\text { No. of patients with } \\
\text { event (cumulative } \\
5 \text {-year incidence, \%) }\end{array}$} & \multirow{2}{*}{$\begin{array}{l}\text { Log-rank } \\
P \text { value }\end{array}$} & \multicolumn{2}{|c|}{ Adjusted } & \multirow{2}{*}{$P$ value } \\
\hline & & & HR & $95 \% \mathrm{Cl}$ & \\
\hline All-cause death/HF hospitalization & & $<0.001$ & & & \\
\hline Direct admission by ambulance & $308(23.5)$ & & 1 (Reference) & & \\
\hline Direct admission by walk-in & $139(19.6)$ & & 1.09 & $(0.88-1.34)$ & 0.44 \\
\hline Inter-facility transfer from a clinic & $110(19.2)$ & & 1.00 & $(0.79-1.25)$ & 0.99 \\
\hline Inter-facility transfer from a hospital & $332(31.5)$ & & 1.42 & $(1.20-1.68)$ & $<0.001$ \\
\hline All-cause death & & $<0.001$ & & & \\
\hline Direct admission by ambulance & 255 (19.7) & & 1 (Reference) & & \\
\hline Direct admission by walk-in & $98(14.0)$ & & 0.95 & $(0.75-1.21)$ & 0.70 \\
\hline Inter-facility transfer from a clinic & $82(14.5)$ & & 0.90 & $(0.69-1.16)$ & 0.42 \\
\hline Inter-facility transfer from a hospital & $280(26.6)$ & & 1.36 & $(1.13-1.63)$ & 0.001 \\
\hline Cardiac death & & $<0.001$ & & & \\
\hline Direct admission by ambulance & $157(12.1)$ & & 1 (Reference) & & \\
\hline Direct admission by walk-in & $58(8.3)$ & & 1.01 & $(0.72-1.38)$ & 0.97 \\
\hline Inter-facility transfer from a clinic & $44(7.6)$ & & 0.90 & $(0.62-1.26)$ & 0.54 \\
\hline Inter-facility transfer from a hospital & $169(16.1)$ & & 1.35 & $(1.07-1.72)$ & 0.01 \\
\hline HF hospitalization & & 0.24 & & & \\
\hline Direct admission by ambulance & $95(8.1)$ & & 1 (Reference) & & \\
\hline Direct admission by walk-in & $59(9.0)$ & & 1.42 & $(0.99-2.01)$ & 0.054 \\
\hline Inter-facility transfer from a clinic & $37(6.7)$ & & 0.96 & $(0.62-1.45)$ & 0.86 \\
\hline Inter-facility transfer from a hospital & $90(10.0)$ & & 1.43 & $(1.05-1.95)$ & 0.02 \\
\hline
\end{tabular}

Abbreviations as in Tables 1,2.

measures to achieve more rapid reperfusion in STEMI.1,23

Inter-facility transfer for primary PCI, on the other hand, will remain even after an increase in direct admissions by ambulance, because some STEMI patients will initially present at non-PCI facilities. In the current study, median transfer distance was only $8 \mathrm{~km}$ in the inter-facility transfer groups. Therefore, treatment delay caused by the transfer itself was quite short, and the majority of treatment delay might be caused by prolonged door-in door-out (DIDO) time. Both the current European Society of Cardiology/European Association for Cardio-Thoracic Surgery and the ACC/AHA clinical guidelines recommend that DIDO time $<30 \mathrm{~min}$ should be implemented in non-PCI centers as a quality metric. ${ }^{1,2}$ However, Wang et al reported that only $11 \%$ of STEMI patients who were initially admitted to a non-PCI center have DIDO times less than the recommended $30 \mathrm{~min}^{24}$ To further improve the clinical outcome of STEMI patients, efforts to minimize DIDO time in non-PCI centers should also be pursued.

It was intriguing to note the differences in the baseline characteristics of the inter-facility transfer and direct admission groups. Patients with advanced age and anemia, who were more prevalent in the inter-facility transfer group, were more likely to have a home doctor or a local hospital to visit. On the other hand, patients with prior MI, who were more prevalent in the direct transfer groups, were more likely to know the symptoms of AMI and the importance of timely reperfusion by PCI, leading to their low threshold of calling the ambulance service. It is crucially important to expand the public campaign regarding the importance of making the total ischemic time as short as possible by lowering the threshold in calling an ambulance when having symptoms suggestive of AMI in order to improve the outcomes of STEMI patients.

\section{Study Limitations}

First, the study had the limitations inherent to observational study design such as selection bias and unmeasured confounders, despite extensive statistical adjustment for potential confounders. The huge differences in the baseline characteristics of the study groups, including the prescription rate of evidence-based medicine such as $\beta$-blockers and angiotensinconverting enzyme inhibitors/angiotensin-receptor blockers, might influence the study results even after adjusting for potential confounders, including medications. Second, we did not know whether the inter-facility transfer patients were actually transferred to the referring facilities by ambulance or by walk-in. Furthermore, we did not have detailed data for these patients at the referring facilities, including DIDO time and the medical therapy. Third, precise data on transfer times were lacking because of the retrospective nature of the current study. Fourth, we did not have data on the attending physician after discharge (cardiologist or general physician). Finally, because the emergency medical service system and distribution of PCI centers in Japan may be different from those outside Japan, generalizing these results to populations outside Japan should be done with caution.

\section{Conclusions}

Inter-facility transfer was significantly associated with longer OTB time and worse long-term clinical outcomes of patients with STEMI undergoing primary PCI, although the majority of the inter-facility transfer patients were transferred from a relatively nearby referring facility in this cohort. Direct admission to PCI centers should be pursued to further improve the outcomes of STEMI patients.

\section{Acknowledgments}

We thank the members of the cardiac catheterization laboratories of the participating centers and the clinical research coordinators. 


\section{Conflict of Interest Statement}

None of the authors has conflicts of interest to disclose regarding this study.

\section{Funding}

The current study was supported by the Health, Labor and Welfare Ministry in Japan, the Health Labor Sciences Research Grant in Japan, and the Pharmaceuticals and Medical Devices Agency (PMDA) in Japan. The Health, Labor and Welfare Ministry in Japan and the PMDA had no role in the study design, in the collection, analysis, and interpretation of data, in the writing of the reports or in the decision to submit the article for publication.

\section{Ethical Approval}

The protocol for the study was approved by the human research ethics committees of the Kyoto University Graduate School of Medicine.

\section{References}

1. O'Gara PT, Kushner FG, Ascheim DD, Casey DE Jr, Chung MK, de Lemos JA, et al. 2013 ACCF/AHA guideline for the management of ST-elevation myocardial infarction: A report of the American College of Cardiology Foundation/American Heart Association Task Force on Practice Guidelines. J Am Coll Cardiol 2013; 61: e78e140, doi:10.1016/j.jacc.2012.11.019.

2. Windecker S, Kolh P, Alfonso F, Collet JP, Cremer J, Falk V, et al. 2014 ESC/EACTS Guidelines on myocardial revascularization: The Task Force on Myocardial Revascularization of the European Society of Cardiology (ESC) and the European Association for CardioThoracic Surgery (EACTS) Developed with the special contribution of the European Association of Percutaneous Cardiovascular Interventions (EAPCI). Eur Heart J 2014; 35: 2541-2619.

3. Flynn A, Moscucci M, Share D, Smith D, LaLonde T, Changezi H, et al. Trends in door-to-balloon time and mortality in patients with ST-elevation myocardial infarction undergoing primary percutaneous coronary intervention. Arch Intern Med 2010; 170: 1842-1849.

4. Menees DS, Peterson ED, Wang Y, Curtis JP, Messenger JC, Rumsfeld JS, et al. Door-to-balloon time and mortality among patients undergoing primary PCI. N Engl J Med 2013; 369: 901-909.

5. Terkelsen CJ, Sørensen JT, Maeng M, Jensen LO, Tilsted HH, Trautner S, et al. System delay and mortality among patients with stemi treated with primary percutaneous coronary intervention. JAMA 2010; 304: 763-771.

6. Terkelsen CJ, Jensen LO, Tilsted HH, Trautner S, Johnsen SP, Vach $\mathrm{W}$, et al. Health care system delay and heart failure in patients with ST-segment elevation myocardial infarction treated with primary percutaneous coronary intervention: Follow-up of population-based medical registry data. Ann Intern Med 2011; 155: 361-367.

7. Shiomi H, Nakagawa Y, Morimoto T, Furukawa Y, Nakano A, Shirai S, et al. Association of onset to balloon and door to balloon time with long term clinical outcome in patients with st elevation acute myocardial infarction having primary percutaneous coronary intervention: Observational study. BMJ 2012; 344: e3257, doi: 10.1136/bmj.e3257.

8. Fosbøl EL, Granger CB, Peterson ED, Lin L, Lytle BL, Shofer FS, et al. Prehospital system delay in ST-segment elevation myocardial infarction care: A novel linkage of emergency medicine services and in hospital registry data. Am Heart J 2013; 165: 363-370.

9. Higuma T, Hanada H, Okumura K. Direct transfer, shorter onset-toballoon time, and better clinical outcome in ST-segment elevation myocardial infarction. Circ J 2015; 79: 1897-1899.

10. Brodie BR, Stuckey TD, Hansen CJ, VerSteeg D, Muncy D, Pulsipher M, et al. Effect of treatment delay on outcomes in patients with acute myocardial infarction transferred from community hospitals for primary percutaneous coronary intervention. Am J Cardiol 2002; 89: $1243-1247$.

11. Le May MR, So DY, Dionne R, Glover CA, Froeschl MP, Wells $\mathrm{GA}$, et al. A citywide protocol for primary PCI in ST-segment elevation myocardial infarction. $N$ Engl J Med 2008; 358: 231-240.

12. Manari A, Ortolani P, Guastaroba P, Casella G, Vignali L, Varani E, et al. Clinical impact of an inter-hospital transfer strategy in patients with ST-elevation myocardial infarction undergoing primary angioplasty: The Emilia-Romagna ST-segment Elevation Acute Myocardial Infarction Network. Eur Heart J 2008; 29: 1834-1842.

13. Wohrle J, Desaga M, Metzger C, Huber K, Suryapranata H, Guetta
$\mathrm{V}$, et al. Impact of transfer for primary percutaneous coronary intervention on survival and clinical outcomes (from the HORIZONSAMI trial). Am J Cardiol 2010; 106: 1218-1224.

14. Wang TY, Peterson ED, Ou FS, Nallamothu BK, Rumsfeld JS, Roe MT. Door-to-balloon times for patients with ST-segment elevation myocardial infarction requiring interhospital transfer for primary percutaneous coronary intervention: A report from the National Cardiovascular Data Registry. Am Heart J 2011; 161: 76-83.

15. Sørensen JT, Terkelsen CJ, Nørgaard BL, Trautner S, Hansen TM, $\mathrm{B} \emptyset t \mathrm{ker} \mathrm{HE}$, et al. Urban and rural implementation of prehospital diagnosis and direct referral for primary percutaneous coronary intervention in patients with acute ST-elevation myocardial infarction. Eur Heart J 2011; 32: 430-436.

16. Le May MR, Wells GA, So DY, Glover CA, Froeschl M, Maloney $\mathrm{J}$, et al. Reduction in mortality as a result of direct transport from the field to a receiving center for primary percutaneous coronary intervention. J Am Coll Cardiol 2012; 60: 1223-1230.

17. Chan AW, Kornder J, Elliott H, Brown RI, Dorval JF, Charania J, et al. Improved survival associated with pre-hospital triage strategy in a large regional ST-segment elevation myocardial infarction program. JACC Cardiovasc Interv 2012; 5: 1239-1246.

18. Fosbøl EL, Granger CB, Jollis JG, Monk L, Lin L, Lytle BL, et al. The impact of a statewide pre-hospital STEMI strategy to bypass hospitals without percutaneous coronary intervention capability on treatment times. Circulation 2013; 127: 604-612.

19. Tarkin J, Malhotra A, Apps A, Smith R, Di Mario C, Rogers P, et al. Inter-hospital transfer for primary angioplasty: Delays are often due to diagnostic uncertainty rather than systems failure and universal time metrics may not be appropriate. EuroIntervention 2015; 11: $511-517$.

20. Imori Y, Akasaka T, Shishido K, Ochiai T, Tobita K, Yamanaka F, et al. Prehospital transfer pathway and mortality in patients undergoing primary percutaneous coronary intervention. Circ J 2015; 79: 2000-2008

21. Ui S, Chino M, Isshiki T. Rates of primary percutaneous coronary intervention worldwide. Circ J 2005; 69: 95-100.

22. Jollis JG, Roettig ML, Aluko AO, Anstrom KJ, Applegate RJ, Babb $\mathrm{JD}$, et al. Implementation of a statewide system for coronary reperfusion for ST-segment elevation myocardial infarction. JAMA 2007; 298: $2371-2380$.

23. Bagai A, Dangas GD, Stone GW, Granger CB. Reperfusion strategies in acute coronary syndromes. Circ Res 2014; 114: 1918-1928.

24. Wang TY, Nallamothu BK, Krumholz HM, Li S, Roe MT, Jollis JG, et al. Association of door-in to door-out time with reperfusion delays and outcomes among patients transferred for primary percutaneous coronary intervention. JAMA 2011; 305: 2540-2547.

\section{Supplementary Files}

Supplementary File 1

Supplementary Methods

Appendix S1. List of Participating Centers and Investigators for the CREDO-Kyoto AMI Registry

Appendix S2. List of Clinical Research Coordinators

Appendix S3. List of the Clinical Event Committee Members

Table S1. Baseline clinical characteristics: direct admission by ambulance vs. direct admission by walk-in vs. transfer from clinic vs. transfer from hospital

Table S2. Multivariable analysis for a composite of all-cause death and HF hospitalization in STEMI patients undergoing PCI

Table S3. Multivariable analysis for all-cause death of STEMI patients undergoing PCI

Table S4. Multivariable analysis for cardiac death of STEMI patients undergoing PCI

Table S5. Multivariable analysis for HF hospitalization of STEMI patients undergoing PCI

Figure S1. (A) Onset-to-presentation, (B) door-to-balloon and (C) onset-to-balloon time according to mode of admission to the percutaneous coronary intervention center.

Please find supplementary file(s);

http://dx.doi.org/10.1253/circj.CJ-16-0204 